\title{
Composição química e perdas fermentativas de silagem de cana-de-açúcar tratada com ureia ou hidróxido de sódio
}

\section{Leandro Sampaio Oliveira Ribeiro ${ }^{1}$, Aureliano José Vieira Pires ${ }^{2}$, Gleidson Giordano Pinto de Carvalho ${ }^{3}$, Alana Batista dos Santos ${ }^{4}$, Antônio Roberto Ferreira ${ }^{5}$, Paulo Bonomo ${ }^{6}$, Fabiano Ferreira da Silva ${ }^{2}$}

\footnotetext{
1 Graduação em Zootecnia, UESB, Itapetinga, BA. Bolsista de Iniciação Científica do CNPq.

2 Departamento de Tecnologia Rural e Animal - DTRA, UESB, Itapetinga, BA. Pesquisador do CNPq

${ }^{3}$ Doutorando em Zootecnia, UFV, Viçosa, MG. Bolsista do CNPq.

${ }^{4}$ Graduação em Zootecnia, UESB, Itapetinga, BA. Bolsista de Iniciação Científica da FAPESB.

5 Empresa Vale Dourado.

${ }^{6}$ Departamento de Estudos Básicos e Instrumentais - DEBI, UESB, Itapetinga, BA.
}

RESUMO - O experimento foi conduzido para avaliar a composição química e as perdas fermentativas de silagens de canade-açúcar tratadas com ureia ou hidróxido de sódio $(\mathrm{NaOH})$. Utilizou-se um delineamento inteiramente casualizado com quatro repetições, em esquema fatorial $2 \times 4$, com duas variedades de cana-de-açúcar (CB 45-3 e RB 72-454) e quatro aditivos (controle, $\mathrm{NaOH}$, ureia ou $\mathrm{NaOH}+$ ureia), compondo as seguintes silagens: cana-de-açúcar sem aditivo; cana-de-açúcar tratada com $4 \%$ de ureia; cana-de-açúcar tratada $4 \%$ de $\mathrm{NaOH}$; cana-de-açúcar tratada com $2 \%$ de ureia $+2 \%$ de $\mathrm{NaOH}$. Os procedimentos foram realizados em ambas as variedades e as doses aplicadas com base na matéria seca. A cana-de-açúcar foi picada e misturada, acescida dos aditivos e armazenada em silos de PVC com $50 \mathrm{~cm}$ de altura por $10 \mathrm{~cm}$ de diâmetro, providos de válvula de Bunsen. Adotouse uma compactação de $750 \mathrm{~kg}$ de matéria natural $/ \mathrm{m}^{3}$. Os silos foram pesados no início e ao final do período experimental para quantificar as perdas por gases e efluente. Não foi observado efeito de interação entre variedades de cana-de-açúcar e doses para perdas por efluente, $\mathrm{pH}$, celulose, lignina e cinza. O hidróxido de sódio contribui para redução de perdas,manutenção do grau brixa e elevação do pH da silagem da cana-de-açúcar, independentemente da utilização da ureia, além de promover redução dos constituintes da parede celular, ocasionando melhoria na qualidade da silagem de cana-de-açúcar.

Palavras-chave: aditivo, ensilagem, nutrição animal, tratamento químico

\section{Chemical composition and fermentative losses of the sugar cane silage treated with urea or sodium hydroxide}

\begin{abstract}
The experiment was conducted to evaluate the chemical composition and fermentation losses of the sugar cane silage treated with urea or sodium hydroxide $(\mathrm{NaOH})$. It was used a completely randomized design with four replicates, in a $2 \times 4$ factorial scheme, with two varieties of cane sugar (CB 45-3, RB 72-454) and four additives (Control, NaOH, urea or $\mathrm{NaOH}+$ urea), composing the following silages: sugar cane without additive; sugar cane treated with $4 \%$ urea; sugar cane treated with $4 \% \mathrm{NaOH}$; sugar cane treated with $2 \%$ urea $+2 \% \mathrm{NaOH}$. The procedures were performed in both varieties and the doses applied in the dry matter basis. The sugar cane was chopped and then mixed, added with additives and stored in PVC silos with $50 \mathrm{~cm}$ of height by $10 \mathrm{~cm}$ of diameter, provided with Bunsem valve. It was adopted a compression of $750 \mathrm{~kg}$ of natural matter $/ \mathrm{m}^{3}$. The silos were weighed at the beginning and at the end of the trial period to quantify the losses by gases and effluent. There was no interaction effect among varieties of sugar cane and doses for effluent losses, $\mathrm{pH}$, cellulose, lignin and ash. Sodium hydroxide contributes for the reduction of losses, maintenance of Brix and $\mathrm{pH}$ raising of the silage of sugar cane, regardless to the use of urea, in addition to promote reduction of the constituents of the cell wall causing improvement on the quality of silage from sugar cane.
\end{abstract}

Key Words: additive, animal nutrition, chemical treatment, ensilage

\section{Introdução}

A conservação de volumosos tem sido utilizada como uma técnica que permite o aproveitamento de forrageiras na alimentação animal em qualquer época do ano, reduzindo os efeitos do período crítico sobre a produção animal.
Embora a cana-de-açúcar seja um alimento com grande potencial para a alimentação de ruminantes, seu uso na forma de silagem não é comum nos atuais sistemas de produção, pois o alto conteúdo de açúcares solúveis presentes nesta forrageira resulta em rápida proliferação de leveduras epífitas que levam à produção de etanol e de $\mathrm{CO}_{2}$ 
(Valvasori et al., 1995), causando perdas excessivas de MS e do valor nutritivo da forragem. Em estudos conduzidos para avaliar a qualidade nutricional da silagem de cana-deaçúcar, Freitas et al. (2006a) e Pedroso et al. (2005) encontraram elevados valores para a perda de MS durante a fermentação: 31,1 e 29,2\%, respectivamente.

Com o intuito de melhorar os padrões de fermentação da silagem de cana-de-açúcar, diversos tipos de aditivos vêm sendo testados para que a ensilagem de cana-deaçúcar seja uma alternativa viável e rentável. Portanto, é neste cenário que inúmeros aditivos químicos vêm sendo pesquisados com a finalidade de controlar a população de leveduras e de propiciar a redução das perdas decorrentes dos processos fermentativos (Queiroz et al., 2008). A adição de ureia na ensilagem baseia-se na transformação dessa ureia em amônia $\left(\mathrm{NH}_{3}\right)$, que reage com água, formando hidróxido de amônia, elevando o $\mathrm{pH}$ e atuando sobre o metabolismo de microrganismos indesejáveis, principalmente leveduras (Kung Junior et al., 2003).

Outro aditivo que apresenta possibilidade de uso na ensilagem de cana-de-açúcar é o $\mathrm{NaOH}$. Em estudo realizado por Freitas et al. (2006b), esse aditivo foi avaliado e recomendado para ser utilizado na ensilagem da cana-deaçúcar pois, segundo os autores, o mesmo foi capaz de alterar a fermentação alcoólica para fermentação predominantemente lática.

Objetivou-se avaliar a composição química e as perdas fermentativas, bem como o grau brix e o pH de silagens de cana-de-açúcar tratadas com ureia ou hidróxido de sódio.

\section{Material e Métodos}

O experimento foi conduzido no Laboratório de Forragicultura e Pastagem da Universidade Estadual do Sudoeste da Bahia (UESB), Campus Juvino Oliveira, localizado no município de Itapetinga, estado da Bahia, a $15^{\circ} 09^{\prime} 07^{\prime \prime}$ de Latitude Sul, 40¹5'32" de Longitude Oeste, precipitação média anual de $800 \mathrm{~mm}$, temperatura média anual de $27^{\circ} \mathrm{C}$ e altitude média de $268 \mathrm{~m}$.

Utilizou-se um esquema fatorial $2 \times 4$, com duas variedades de cana-de-açúcar (CB 45-3, RB 72-454) e quatro aditivos (hidróxido de sódio, ureia, hidróxido de sódio + ureia), em delineamento inteiramente casualizado, com quatro repetições, estabelecidas da seguinte forma: silagem de cana-de-açúcar sem aditivo; silagem de cana-de-açúcar tratada com 4\% de ureia; silagem de cana-de-açúcar tratada $4 \%$ de $\mathrm{NaOH}$ e silagem de cana-de-açúcar tratada com $2 \%$ de ureia $+2 \%$ de $\mathrm{NaOH}$, sendo que estes aditivos foram realizados em ambas as variedades e as doses aplicadas com base na matéria seca, o que correspondeu a 1,12 e 0,56\% com base na matéria natural (peso/peso), respectivamente, para as doses 4 e $2 \%$ independentemente do aditivo.

Os cultivares de cana-de-açúcar provenientes da Estação Experimental Manuel Machado (EBDA), no município de Itambé, Bahia, foram desintegradas em ensiladeira estacionária regulada para cortar a forragem em partículas de aproximadamente $10 \mathrm{~mm}$ de comprimento, homogeneizadas, tratadas conforme os respectivos procedimentos e ensilados em seguida, em silos de PVC com $50 \mathrm{~cm}$ de altura por $10 \mathrm{~cm}$ de diâmetro, providos de válvula de Bunsen, areia e tela no fundo. A compactação utilizada neste experimento foi de $750 \mathrm{~kg}$ de matéria verde $/ \mathrm{m}^{3}$.

Os silos com apenas areia e tela no fundo foram previamente pesados, para quantificar o efluente que, por ventura, fosse liberado da cana-de-açúcar, e medidos por ocasião de sua abertura. Após a devida compactação, os silos foram vedados, pesados, e ficaram armazenados por 30 dias. Após o período de armazenamento, os silos foram novamente pesados para se obterem as perdas por gases. Em seguida, foram abertos para a retirada de amostras das silagens, e novamente pesados com a areia e tela no fundo do silo para se obter as perdas ocorridas por efluente.

Foram retiradas amostras das duas variedades de canade-açúcar in natura, para determinação da composição química e do grau brix (Tabela 1).

As amostras coletadas foram colocadas em sacos hermeticamente fechados, identificados e armazenados em freezer a $-10^{\circ} \mathrm{C}$. Para todas as amostras, determinou-se o $\mathrm{pH}$ das silagens no momento da abertura dos silos utilizando o medidor de $\mathrm{pH}$ de bancada. Este procedimento foi realizado por meio da pesagem de $50 \mathrm{~g}$ de cada amostra da silagem, triturada com $200 \mathrm{~mL}$ de água, em liquidificador industrial, e filtrada em gaze para extração do meio aquoso, sendo imediatamente levada para aferição do $\mathrm{pH}$, segundo metodologia de Silva \& Queiroz (2002).

Para a realização das análises químicas, as amostras coletadas em cada silo foram pré-secas em estufa de ventilação forçada a $65^{\circ} \mathrm{C}$, por 72 horas, sendo posteriormente processadas em moinho tipo "Wiley" com peneira de crivos de $1 \mathrm{~mm}$.

Tabela 1 - Composição nutricional e grau brix de duas variedades de cana-de-açúcar in natura antes da ensilagem

\begin{tabular}{lcc}
\hline Item & CB 45-3 & RB 72-454 \\
\hline Matéria seca & 27,5 & 26,2 \\
Proteína bruta (\% da MS) & 3,9 & 3,6 \\
Fibra em detergente neutro (\% da MS) & 45,5 & 51,9 \\
Fibra em detergente ácido (\% da MS) & 29,6 & 31,4 \\
Celulose (\% da MS) & 18,9 & 22,0 \\
Hemicelulose (\% da MS) & 15,9 & 20,5 \\
Lignina (\% da MS) & 10,7 & 11,1 \\
Grau brix & 17,9 & 15,1 \\
\hline
\end{tabular}


Foram avaliados os teores de matéria seca (MS), nitrogênio total (NT), fibra em detergente neutro (FDN), fibra em detergente ácido (FDA), celulose, hemicelulose e lignina, conforme procedimentos descritos por Silva \& Queiroz (2002). O grau brix foi determinado por meio de refratômetro manual.

Os dados de perdas das silagens (gases e efluente), bem como as análises químicas, foram avaliados por meio de análise de variância, e as médias comparadas pelo teste Tukey, adotando o nível de 5\% de probabilidade. Para realizar as análises estatísticas, foi utilizado o programa SAEG (Ribeiro Jr., 2001).

\section{Resultados e Discussão}

Verificou-se efeito de interação $(\mathrm{P}<0,05)$ entre variedade da cana-de-açúcar e aditivos para grau brix (Tabela 2). Observa-se que, para os aditivos contendo hidróxido de sódio $(\mathrm{NaOH})$, o grau brix se manteve mais elevado independente da variedade utilizada. Por outro lado, as silagens com $4 \%$ de $\mathrm{NaOH}$ e $2 \%$ de ureia $+2 \%$ de $\mathrm{NaOH}$, apresentaram valores médios, respectivamente, de 16,1 e $15,0 \%$. Valores estes aproximados ao do valor do brix das respectivas, cana-de-açúcar in natura (Tabela 1). Este fato comprova a eficiência do aditivo $\mathrm{NaOH}$ em controlar o desenvolvimento de microrganismos, os quais consomem os carboidratos solúveis da cana-de-açúcar, produzindo substâncias secundárias da fermentação que podem promover benefícios ou processos degenerativas na obtenção do produto final (silagem).

O grau brix pode ser caracterizado como uma análise subjetiva, por quantificar apenas a quantidade total de

Tabela 2 - Grau brix e pH de silagens de duas variedades de cana-de-açúcar tratadas com ureia e hidróxido de sódio

\begin{tabular}{|c|c|c|c|}
\hline \multirow[t]{2}{*}{ Aditivo } & \multicolumn{2}{|c|}{ Variedade } & \multirow[t]{2}{*}{ Média } \\
\hline & CВ $45-3$ & RB 72-454 & \\
\hline & \multicolumn{2}{|c|}{ Grau brix } & \\
\hline Controle & $7,5 \mathrm{bC}$ & $9,5 \mathrm{aC}$ & 8,5 \\
\hline $4 \%$ ureia & $10,3 \mathrm{aB}$ & $11,3 \mathrm{aB}$ & 10,7 \\
\hline $4 \% \mathrm{NaOH}$ & $17,5 \mathrm{aA}$ & $14,8 \mathrm{bA}$ & 16,1 \\
\hline $2 \%$ ureia $+2 \% \mathrm{NaOH}$ & $16,3 \mathrm{aA}$ & $13,8 \mathrm{bA}$ & 15,0 \\
\hline Média & 12,9 & 12,3 & \\
\hline \multicolumn{4}{|l|}{$C V(\%)=7,0$} \\
\hline \multicolumn{4}{|c|}{$\mathrm{pH}$} \\
\hline Controle & 3,49 & 3,52 & $3,50 \mathrm{~d}$ \\
\hline $4 \%$ ureia & 3,60 & 3,54 & $3,57 c$ \\
\hline $4 \% \mathrm{NaOH}$ & 4,27 & 4,21 & $4,24 \mathrm{a}$ \\
\hline $2 \%$ ureia $+2 \% \mathrm{NaOH}$ & 3,98 & 4,03 & $4,00 \mathrm{~b}$ \\
\hline Média & $3,84 \mathrm{a}$ & $3,82 \mathrm{a}$ & \\
\hline $\mathrm{CV}(\%)=1,3$ & & & \\
\hline
\end{tabular}

Médias seguidas de mesma letra minúscula/maiúscula em mesma linha/coluna não diferem entre si pelo teste Tukey a 5\% de probabilidade. carboidratos solúveis por meio de uma escala numérica. Por este motivo, não é um bom indicativo de qualidade fermentativa quando analisado isoladamente. Mesmo assim, indica o momento certo do corte da cana-de-açúcar.

A silagem de cana-de-açúcar com $4 \%$ de ureia apresentou maiores valores médios de grau brix (10,7\%) em comparação à silagem controle (8,5\%), independentemente da variedade utilizada. Entretanto, a utilização do $\mathrm{NaOH}$ na ensilagem apresentou valores de grau brix superiores à silagem com $4 \%$ de ureia e à controle.

Quando utilizada na forma de silagem, o elevado teor de açúcares solúveis na cana-de-açúcar pode resultar em um produto com intensa fermentação alcoólica (Peixoto, 1994). Relacionando-se essa informação aos resultados observados no presente estudo, fica clara a necessidade da inclusão de algum tipo de aditivo a fim de reduzir a fermentação alcoólica, que, apesar de não ter sido medida no experimento, indica que a manutenção dos valores observados para o grau brix das silagens com ureia e $\mathrm{NaOH}$ possibilita a ocorrência de baixos processos fermentativos.

Não foi verificado efeito de interação $(\mathrm{P}>0,05)$ entre variedades de cana-de-açúcar e aditivos para o pH. Porém, verificou-se efeito $(\mathrm{P}<0,05)$ para aditivos (Tabela 2$)$. Os valores de $\mathrm{pH}$ apresentaram-se mais elevados para as silagens com $4 \%$ de $\mathrm{NaOH}(4,24)$, seguido da silagem com $2 \%$ ureia $+2 \% \mathrm{NaOH}(4,00)$, silagem com $4 \%$ de ureia $(3,57)$ e, posteriormente, a silagem controle $(3,50)$. Entretanto, estes valores apresentados estão dentro de um patamar adequado à conservação, uma vez que, de acordo com Mc Donald et al (1991), silagens de boa qualidade podem apresentar pH entre 3,6 a 4,2. O que não era de se esperar quando foram utilizados os aditivos $\mathrm{NaOH}$ ou ureia, pois estes apresentam um caráter alcalino e, ao reagirem no processo de ensilagem, podem aumentar o poder tampão da massa ensilada, o que viria a dificultar a queda do $\mathrm{pH}$ (Siqueira et al., 2007b).

Resultados semelhantes foram encontrados por Freitas et al. (2006b), que observaram as características da silagem de cana-de-açúcar tratada com aditivos microbianos (Lactobacillus plantarum) ou químicos ( $\mathrm{NaOH}, 3 \%$ na MS) e acrescido de resíduos da colheita de soja (10\%, na MN) e verificaram que a cana-de-açúcar tratada com $3 \%$ de $\mathrm{NaOH}$ ou com resíduo da colheita $+3 \%$ de $\mathrm{NaOH}$, apresentaram valores de pH, respectivamente, de 3,72 e 3,83. Possivelmente estes resultados foram menores devido ao aditivo $\mathrm{NaOH}$ ter sido adicionado em menor quantidade. Resultados divergentes aos encontrados no presente trabalho foram relatados por Siqueira et al. (2007a) ao avaliarem a associação entre aditivos químicos e bacterianos na ensilagem de canade-açúcar, observando que, no momento da abertura dos 
silos que continham ureia $(1,5 \%$ com base na matéria natural), os valores médios de $\mathrm{pH}$ foram de 4,4, já para os que continham $\mathrm{NaOH}$ (1,0\% com base na matéria natural) os valores médios foram de 4,6.

Schmidt et al. (2007) afirmaram que variações estatísticas entre valores de $\mathrm{pH}$ encontrados nas silagens têm pouca importância biológica, pois estudos apontam que o pH não é um ponto crítico em silagens de cana-de-açúcar e tampouco indicador de qualidade fermentativa.

Verificou-se efeito de interação $(\mathrm{P}<0,05)$ entre variedades de cana-de-açúcar e aditivos para perdas por gases (Tabela 3). Menores efeitos de perdas foram observados para as silagens de cana-de-açúcar com 4\% de $\mathrm{NaOH}$, seguido da silagem com $2 \%$ de ureia $+2 \%$ de $\mathrm{NaOH}$. Esse fato deve estar associado à inibição ocasionada pelo $\mathrm{NaOH}$ sobre o crescimento de bactérias e fungos presentes no silo que, por sua vez, utilizariam o açúcar da cana-deaçúcar para se desenvolver, produzindo etanol e $\mathrm{CO}_{2}$.

Siqueira et al. (2007b), avaliando as perdas de silagens de cana-de-açúcar tratadas com aditivos químicos (1,5\% de ureia - $35 \mathrm{~L} / \mathrm{t}$ de MV; 0,1\% de benzoato de sódio e 1\% de $\mathrm{NaOH}-30 \mathrm{~L} / \mathrm{t}$ de MV) ou bacterianos (P. acidipropionici; $L$. plantarum e L. bucheneri), observaram que entre as silagens tratadas com aditivos químicos, aqueles tratamentos com $\mathrm{NaOH}$ tiveram as menores perdas por gases, sendo observado valores de 9,6 e 13,2 (\% MS) para os tratamentos $\mathrm{NaOH}$ e ureia, estabelecendo uma diferença de 37,5\% entre os tratamentos. Resultados semelhantes foram encontrados no presente estudo que comprovam a eficiência do $\mathrm{NaOH}$ na redução das perdas por gases, na ensilagem de cana-de-açúcar.

Tabela 3 - Perdas por gases e por efluente de silagens de canade-açúcar tratadas com ureia e hidróxido de sódio

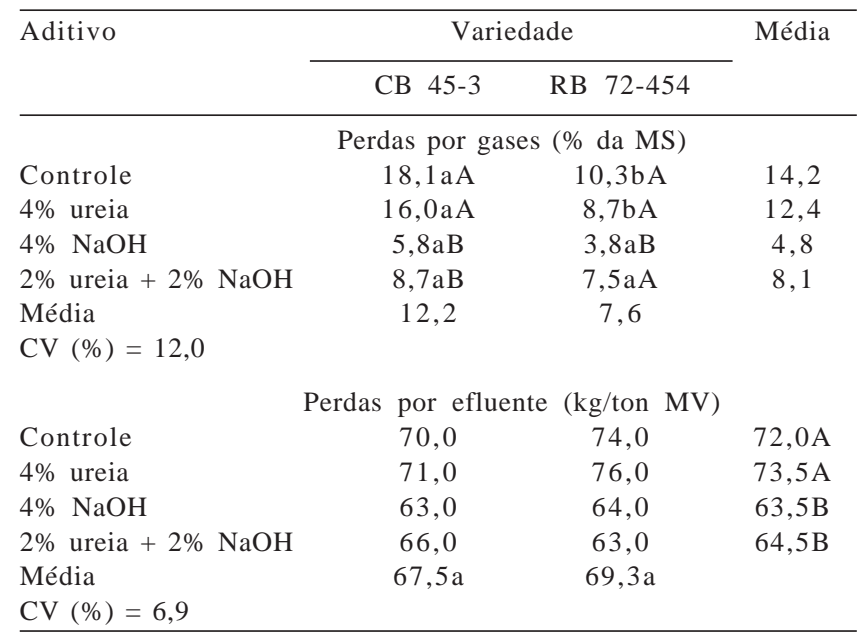

Médias seguidas por uma mesma letra minúscula/maiúscula em uma mesma linha/ coluna não diferem pelo teste Tukey a 5\% de probabilidade.
Não foi verificado efeito de interação $(\mathrm{P}>0,05)$ entre variedades de cana-de-açúcar e aditivos para perdas por efluentes. No entanto, verificou-se efeito $(\mathrm{P}<0,05)$ de perdas por efluente apenas em função de aditivos, em que os menores valores foram apresentados para a cana-de-açúcar ensilada com $\mathrm{NaOH}$, sendo que as silagens de cana-deaçúcar com $4 \%$ de $\mathrm{NaOH}$ ou com $2 \%$ de ureia $+2 \%$ de $\mathrm{NaOH}$ apresentaram valores, respectivamente, de 63,5 e $64,5 \mathrm{~kg} / \mathrm{t}$ de MV.

De modo geral, apesar das médias apresentarem um comportamento estatístico diferenciado entre os aditivos, os valores se apresentam muito próximos para as perdas por efluentes (Tabela 3), ocasionadas pela baixa retenção de umidade da cana-de-açúcar quando compactada.

Entretanto, esta quantidade de efluente que se perde ao ensilar a cana-de-açúcar implica na perda de nutrientes que são carreados para o fundo do silo, deixando a massa ensilada com menor teor de nutrientes solúveis que o material in natura. Contudo, deve-se atentar para a necessidade de aditivos com o intuito de reduzir a umidade da cana-de-açúcar e, consequentemente, reduzir as perdas por efluente.

Siqueira et al. (2007b), avaliando as perdas de silagens de cana-de-açúcar tratadas com aditivos químicos e bacterianos, afirmam que alguns fatores podem estar relacionados com a maior ou menor produção de efluentes. O primeiro relacionado é a picagem do material, pois, apesar de não ter sido quantificada no presente trabalho, fragmentos muito pequenos ocasionam maior produção de efluentes. Outro fator que pode superestimar a produção de efluentes é o processo de ensilagem em silos experimentais de PVC, pois os bastões de ferro utilizados na compactação da forragem apresentam diâmetro próximo ao dos silos, o que proporciona uma compactação sobre toda sua superfície, podendo provocar maior dilaceração das partículas ensiladas, tendo como consequência maior produção de efluentes.

Verificou-se efeito de interação $(\mathrm{P}<0,05)$ entre variedades de cana-de-açúcar e aditivos para variável MS (Tabela 4). As variedades de cana-de-açúcar CB45-3 e RB72-454, quando tratadas com $2 \%$ de ureia $+2 \%$ de $\mathrm{NaOH}$ ou $4 \%$ de $\mathrm{NaOH}$, apresentaram maiores valores de MS (27,1; 23,7\% e 25,$0 ; 21,8 \%$, respectivamente), seguidas pelas silagens com $4 \%$ de ureia com valores de 20,6 e 20,5\%. Entretanto, a silagem controle foi a que apresentou menores valores de MS (19,4 e 18,1\%).

Os teores de MS da cana-de-açúcar in natura (Tabela 1) podem ser considerados adequados para ensilagem dessa forrageira. Contudo, as variações observadas entre a canade-açúcar in natura, pós-abertura e até mesmo as diferenças 
Tabela 4 - Matéria seca, fibra em detergente neutro e fibra em detergente ácido de silagens de cana-de-açúcar tratadas com ureia e hidróxido de sódio

\begin{tabular}{|c|c|c|c|}
\hline \multirow[t]{2}{*}{ Aditivo } & \multicolumn{2}{|c|}{ Variedade } & \multirow[t]{2}{*}{ Média } \\
\hline & CB $45-3$ & RB $72-454$ & \\
\hline \multicolumn{4}{|c|}{ Matéria seca } \\
\hline Controle & $19,4 \mathrm{aB}$ & $18,1 \mathrm{a} C$ & 18,7 \\
\hline $4 \%$ ureia & $20,6 \mathrm{aB}$ & 20,5 a B & 20,5 \\
\hline $4 \% \mathrm{NaOH}$ & $25,0 \mathrm{aB}$ & $21,8 \mathrm{~b} \mathrm{AB}$ & 23,3 \\
\hline $2 \%$ ureia $+2 \% \mathrm{NaOH}$ & $27,1 \mathrm{aA}$ & $23,7 \mathrm{bAB}$ & 25,4 \\
\hline Média & 23,0 & 21,0 & \\
\hline $\mathrm{CV}(\%)=4,9$ & & & \\
\hline \multicolumn{4}{|c|}{ Fibra em detergente neutro ( $\%$ da MS) } \\
\hline Controle & $74,5 \mathrm{aA}$ & $65,0 \mathrm{bA}$ & 69,7 \\
\hline $4 \%$ ureia & 66,9 aB & $59,8 b B$ & 63,3 \\
\hline $4 \% \mathrm{NaOH}$ & $48,8 \mathrm{aD}$ & $50,6 \mathrm{aD}$ & 49,7 \\
\hline $2 \%$ ureia $+2 \% \mathrm{NaOH}$ & $53,2 \mathrm{aC}$ & $55,6 \mathrm{aC}$ & 54,4 \\
\hline Média & 60,8 & 57,7 & \\
\hline $\mathrm{CV}(\%)=3,3$ & & & \\
\hline \multicolumn{4}{|c|}{ Fibra em detergente ácido (\% da MS) } \\
\hline Controle & $47,5 \mathrm{aA}$ & $42,0 \mathrm{bA}$ & 44,7 \\
\hline $4 \%$ ureia & $47,2 \mathrm{aA}$ & $40,0 \mathrm{bA}$ & 43,6 \\
\hline $4 \% \mathrm{NaOH}$ & $35,2 \mathrm{aB}$ & $36,0 \mathrm{aB}$ & 35,6 \\
\hline $2 \%$ ureia $+2 \% \mathrm{NaOH}$ & $35,2 \mathrm{aB}$ & $35,6 \mathrm{aB}$ & 35,4 \\
\hline Média & 41,3 & 38,4 & \\
\hline $\mathrm{CV}(\%)=4,5$ & & & \\
\hline
\end{tabular}

Médias seguidas por uma mesma letra minúscula/maiúscula em mesma linha/ coluna não diferem pelo teste Tukey a $5 \%$ de probabilidade.

entre tratamentos na pós-abertura podem ser atribuídas, possivelmente, às perdas durante o processo fermentativo da ensilagem. Portanto, essa redução observada entre os tratamentos pode também ser atribuída ao consumo de carboidratos solúveis durante a fermentação, explicando assim os menores valores de MS observados para os tratamentos controle e $4 \%$ de ureia, que por sua vez não foram eficientes em controlar a fermentação.

Verificou-se efeito de interação $(\mathrm{P}<0,05)$ entre variedades de cana-de-açúcar e aditivos para FDN e FDA (Tabela 4). Os valores de FDN apresentaram maiores reduções para as silagens das variedades CB45-3 e RB72454 tratadas com $4 \%$ de $\mathrm{NaOH}$, com valores médios, respectivamente, de 48,8 e 50,6\%, seguido da combinação $2 \%$ de ureia $+2 \%$ de $\mathrm{NaOH}$ (53,2 e 55,6\%), $4 \%$ de ureia (66,9 e $59,8 \%)$ e posteriormente, as silagens controle $(74,5$ e $65,0 \%)$.

Ao confrontar os teores de fibra das silagens das variedades CB45-3 (74,5\%) e RB72-454 (65,0\%) da silagem controle com as silagens das mesmas variedades, porém com $4 \%$ de $\mathrm{NaOH}$, respectivamente, 48,8 e 50,6\%, verificam-se expressivas reduções para as silagens tratadas com $\mathrm{NaOH}$, observando-se, respectivamente, valores de 52,7 e 28,5\%. Os efeitos das doses dos aditivos sobre os teores de FDN sugerem a ocorrência de hidrólise alcalina com solubilização parcial da hemicelulose (Reis et al., 1991). No entanto, a preservação da fração solúvel também resulta em reduções nos teores de fibra (Balieiro Neto et al., 2007).

Outro fator muito importante é que, exceto a silagem com $4 \%$ de $\mathrm{NaOH}$, em todas as outras silagens produzidas, os teores de fibra da cana-de-açúcar (pós-abertura) aumentaram em comparação à cana-de-açúcar in natura (Tabela 1). Provavelmente estes resultados estão relacionados ao consumo de carboidratos solúveis durante a fermentação, o que resultaria em uma silagem com $\mathrm{pH}$ baixo. Porém, para o tratamento com $4 \%$ de $\mathrm{NaOH}$ isso não foi observado (Tabela 2), podendo relacionar-se também com as perdas por efluentes onde, por perda da fração orgânica solúvel, os teores da fração orgânica insolúveis aumentam. Da mesma maneira, no tratamento com $\mathrm{NaOH}$ não se observou maiores perdas de efluentes (Tabela 3). Portanto, o aditivo $\mathrm{NaOH}$ foi eficiente em reduzir o consumo de carboidratos solúveis durante a ensilagem e na regulação das perdas por efluente.

O aumento nos teores de FDN após a ensilagem está de acordo com os resultados obtidos por Evangelista et al. (2003). Avaliando o perfil de fermentação na ensilagem da cana-de-açúcar, observaram elevação de teor de FDN de 59,6 para 75,6\% após 50 dias de fermentação. Da mesma forma, Castro Neto et al. (2003) também verificaram elevação dos teores de FDN, da ordem de 55,1 para 72,9\% na canade-açúcar ensilada sem aditivo.

Semelhante aos resultados verificados para a FDN, a variável FDA apresentou melhores resultados para a canade-açúcar tratada com $\mathrm{NaOH}$. As silagens com $4 \%$ de $\mathrm{NaOH}$ ou 2\% de ureia $+2 \%$ de $\mathrm{NaOH}$ apresentaram valores médios semelhantes (35,6 e 35,4\%), independente da variedade utilizada, seguida dos respectivos tratamentos com $4 \%$ de ureia e controle que, por sua vez, também apresentaram valores médios semelhantes (43,6 e 44,7\%) independentes da variedade de cana-de-açúcar utilizada.

O aumento nos teores de FDA entre a cana-de-açúcar a ser ensilada e após-abertura do silo já era esperado, já que, assim como a FDN, esse incremento pode ser atribuído ao consumo de carboidratos solúveis por microrganismos durante a ensilagem. Mesmo assim, diferenças maiores entre o material a ser ensilado e a silagem após-abertura foram verificados nos tratamentos $4 \%$ de ureia e controle (Tabela 1), demonstrando o grande potencial do $\mathrm{NaOH}$ como regulador dos processos fermentativos da ensilagem.

Schimidt et al. (2007), avaliando a ação de aditivos químicos $(0,5 \%$ de ureia e $0,1 \%$ de benzoato de sódio em $\% \mathrm{MV}$ ) e biológicos (Lactobacillus plantarum e Lactobacillus bucheneri) na ensilagem de cana-de-açúcar, verificaram que, para os valores de FDN e FDA, a silagem de cana-de-açúcar tratada com $0,5 \%$ de ureia apresentou 
menores teores (61,5 e 39,4\%). Além disso, observaram elevação percentual nas frações da FDN e FDA em relação à cana-de-açúcar fresca, que foi, respectivamente, de 18,8 e $14,4 \%$

Foi verificado efeito de interação $(\mathrm{P}<0,05)$ entre variedade de cana-de-açúcar e aditivos para a variável hemicelulose. Já para as variáveis celulose e lignina, verificou-se efeito $(\mathrm{P}<0,05)$ apenas para aditivos (Tabela 5).

Os teores de hemicelulose da silagem controle foram superiores (27,0\%) aos da silagem com aditivo para a variedade CB 45-3 e semelhantes entre os tratamentos $4 \%$ de ureia $(19,7 \%)$ e $2 \%$ de ureia $+2 \%$ de $\mathrm{NaOH}(18,0 \%)$. Já para a variedade RB 72-454, os tratamentos controle, $4 \%$ de ureia e $2 \%$ de ureia $+2 \%$ de $\mathrm{NaOH}$ apresentaram valores semelhantes, respectivamente, de 21,$5 ; 19,7$ e $20,0 \%$. No entanto, os menores teores de hemicelulose foram verificados para o tratamento com $4 \%$ de $\mathrm{NaOH}$, sendo que para as variedades CB 45-3 e RB 72-454 os valores médios observados foram, respectivamente, de 13,6 e 14,6\% (Tabela 5).

No pós-abertura os teores de hemicelulose foram maiores nas silagens tratada com $4 \%$ de ureia e controle. Como a hemicelulose é obtida a partir da diferença entre a FDN e FDA, o menor efeito da ureia em reduzir os teores de FDA em relação ao $\mathrm{NaOH}$ pode explicar os resultados.

$\mathrm{O}$ teor de celulose da silagem tratada com $\mathrm{NaOH}$ foi inferior ao da silagem tratada com ureia e a controle. Teores médios de celulose de $25,8 \%$ foram observados para a

Tabela 5 - Hemicelulose, celulose e lignina de silagens de canade-açúcar tratadas com ureia e hidróxido de sódio

\begin{tabular}{|c|c|c|c|}
\hline \multirow[t]{2}{*}{ Aditivo } & \multicolumn{2}{|c|}{ Variedade } & \multirow[t]{2}{*}{ Média } \\
\hline & CB $45-3$ & RB $72-454$ & \\
\hline & \multicolumn{2}{|c|}{ Hemicelulose (\% da MS) } & \\
\hline Controle & $27,0 \mathrm{aA}$ & $21,5 \mathrm{bA}$ & 24,3 \\
\hline $4 \%$ ureia & $19,7 \mathrm{aB}$ & $19,7 \mathrm{aA}$ & 19,7 \\
\hline $4 \% \mathrm{NaOH}$ & $13,6 \mathrm{aC}$ & $14,6 \mathrm{aB}$ & 14,1 \\
\hline $2 \%$ ureia $+2 \% \mathrm{NaOH}$ & $18,0 \mathrm{aB}$ & $20,0 \mathrm{aA}$ & 19,0 \\
\hline Média & 19,5 & 18,9 & \\
\hline \multicolumn{4}{|l|}{$\mathrm{CV}(\%)=10,4$} \\
\hline & \multicolumn{2}{|c|}{ Celulose (\% da MS) } & \\
\hline Controle & 35,5 & 30,7 & $33,0 \mathrm{~A}$ \\
\hline $4 \%$ ureia & 33,6 & 29,5 & $31,5 \mathrm{~A}$ \\
\hline $4 \% \mathrm{NaOH}$ & 26,8 & 24,8 & $25,8 \mathrm{~B}$ \\
\hline $2 \%$ ureia $+2 \% \mathrm{NaOH}$ & 26,9 & 25,7 & $26,3 \mathrm{~B}$ \\
\hline Média & $30,6 a$ & $27,7 a$ & \\
\hline \multicolumn{4}{|l|}{$\mathrm{CV}(\%)=7,6$} \\
\hline & \multicolumn{2}{|c|}{ Lignina (\% da MS) } & \\
\hline Controle & 11,6 & 12,1 & $11,8 \mathrm{~A}$ \\
\hline $4 \%$ ureia & 10,7 & 10,0 & $10,4 \mathrm{AB}$ \\
\hline $4 \% \mathrm{NaOH}$ & 8,4 & 9,4 & $8,9 \mathrm{~B}$ \\
\hline $2 \%$ ureia $+2 \% \mathrm{NaOH}$ & 8,2 & 9,9 & $9,0 \mathrm{~B}$ \\
\hline Média & $9,7 \mathrm{a}$ & $10,3 a$ & \\
\hline $\mathrm{CV}(\%)=6,9$ & & & \\
\hline
\end{tabular}

Médias seguidas de mesma letra minúscula/maiúscula em mesma linha/coluna não diferem pelo teste Tukey a 5\% de probabilidade. silagem de cana-de-açúcar com 4\% de $\mathrm{NaOH}$, de 26,3\% para a silagem com $2 \%$ de ureia $+2 \%$ de $\mathrm{NaOH}$ seguida pelos tratamentos $4 \%$ de ureia e controle que apresentaram valores médios, respectivamente, de 31,5 e 33,0\% comprovando a eficiência do $\mathrm{NaOH}$ em reduzir os constituintes da parede celular, melhorando a qualidade da silagem.

$\mathrm{O}$ fato observado nas silagens $\mathrm{com} \mathrm{NaOH}$ pode se atribuído à reação imediata que ocorre após a sua aplicação na cana-de-açúcar, pois claramente percebe-se a elevação da temperatura, e tudo leva a crer que neste momento esteja ocorrendo a solubilização dos constituintes da parede celular. Esta suposição pode ser confirmada no trabalho conduzido por Pires et al. (2006), avaliando o efeito da utilização de doses de $\mathrm{NaOH}(0 ; 2,5 ; 5,0$ e 7,5\% na MS) na estocagem do bagaço da cana-de-açúcar durante 1, 3, 5 e 7 dias e não constataram efeito do tempo em nenhum dos constituintes da parede celular, apesar de ter observado redução dos teores de fibra ocasionadas pelo $\mathrm{NaOH}$, o que vem a comprovar a rápida atuação da hidrólise alcalina.

Os teores de lignina diferiram $(\mathrm{P}<0,05)$ entre as doses dos aditivos utilizados, sendo observado que os menores valores foram constatados para a silagem de cana-deaçúcar com 4\% de $\mathrm{NaOH}(8,9 \%)$ e a silagem com 2\% de ureia + $2 \%$ de $\mathrm{NaOH}$ (9,0\%), seguidos pelas silagens com $4 \%$ de ureia $(10,4 \%)$ e o controle $(11,8 \%)$ independente da variedade utilizada. Os resultados numéricos demonstram que o tratamento alcalino promove reduções na lignina, entretanto, estatisticamente o $\mathrm{NaOH}$ é tão eficiente quanto a associação entre a ureia e o $\mathrm{NaOH}$, por apresentarem resultados semelhantes. Assim, Van Soest (1987) mencionou que durante o tratamento alcalino, parte da lignina e da sílica pode ser dissolvida.

O teor de lignina para a cana-de-açúcar in natura variedade CB45-3 foi de 10,7\% e para variedade RB72-454 o valor foi de $11,1 \%$ (Tabela 1 ). Após o tratamento com $4 \%$ de $\mathrm{NaOH}$ os teores de lignina foram, respectivamente, de 8,4 e 9,4\%, verificando-se reduções, respectivamente, de 2,3 e 1,7 pontos percentuais. No entanto, não foi observado alteração nos teores de lignina para a silagem com $4 \%$ de ureia, quando comparado com a silagem controle independente da variedade, já para a silagem com $2 \%$ de ureia $+2 \%$ de $\mathrm{NaOH}$ observou-se uma gradual redução no teor de lignina, verificando-se reduções de 2,5 e 1,2 pontos percentuais em relação à silagem controle para as variedades CB45-3 e RB72-454, sendo atribuído este resultado à maior ação do $\mathrm{NaOH}$ em reduzir os constituintes da parede celular que a ureia.

Existem vários trabalhos científicos (Freitas et al., 2006b; Siqueira et al., 2007a; Siqueira et al., 2007b; Balieiro Neto et al., 2007) que demonstram a eficiência dos aditivos 
químicos em reduzir os teores de lignina, sendo estes resultados importantes, pois este composto fenólico é o principal limitante da degradação da fração fibrosa de forrageiras. Pedroso et al. (2007), avaliando o efeito da utilização de aditivos químicos (ureia 0,5; 1,0; 1,5\% - $35 \mathrm{~L}$ / t MV, $\mathrm{NaOH} 1,0 ; 2,0 ; 3,0 \%$ - solução comercial a 50\%, Propionato de cálcio, Benzoato de sódio e Sorbato de potássio) e inoculantes bacterianos (Lactobacillus bucheneri e Lactobacillus plantarum) na qualidade de silagens de cana-de-açúcar, observaram reduções de 7,86\% da canade-açúcar in natura para 5,94 e 5,91\% para cana-de-açúcar tratada com 2 e $3 \%$ de $\mathrm{NaOH}$, no entanto para os tratamentos com ureia nas doses 0,$5 ; 1,0$ e 1,5\% não foi observado reduções significativas.

Não se verificou $(P>0,05)$ efeito de interação entre variedades de cana-de-açúcar e aditivos para a variável cinza, porém foi verificado efeito $(\mathrm{P}<0,05)$ apenas para aditivos (Tabela 6). Maiores teores de cinza foram observados para os tratamentos com $4 \%$ de $\mathrm{NaOH}(7,7 \%)$ e $2 \%$ de ureia $+2 \%$ de $\mathrm{NaOH}(5,7 \%)$. Já a silagem controle e $4 \%$ de ureia apresentaram valores inferiores (4,3 e 4,2\%), porém semelhantes entre si. Estes resultados podem ser atribuídos à elevada concentração do mineral sódio ( $\mathrm{Na}$ ) $58 \%$ presente na composição do $\mathrm{NaOH}$. Neste sentido, ressalta-se que em um eventual sistema de alimentação no qual se pretende utilizar a cana-de-açúcar hidrolisada com $\mathrm{NaOH}$ como volumoso, o balanceamento de minerais na dieta total é um importante item a ser considerado.

Resultados semelhantes aos discutidos no presente trabalho foram relatados por Pires et al. (2006), que estudaram o tratamento do bagaço de cana-de-açúcar com $\mathrm{NaOH}$ e relataram que o teor de sódio no bagaço de cana-de-açúcar hidrolisado aumentou linearmente, $0,28 \%$ para cada unidade percentual de $\mathrm{NaOH}$ adicionada. Elevação nos teores de cinzas por ocasião do uso do $\mathrm{NaOH}$ também foi observada por Pedroso et al. (2007), que avaliaram o efeito da utilização de aditivos químicos (ureia 0,5; 1,0; 1,5\% - 35 L/t MV, NaOH

Tabela 6 - Teor de cinza de silagens de cana-de-açúcar tratadas com ureia e hidróxido de sódio

\begin{tabular}{lccc}
\hline Aditivo & \multicolumn{2}{c}{ Variedade } & \multirow{2}{*}{ Média } \\
\cline { 2 - 3 } & CB 45-3 & RB 72-454 & \\
\hline Controle & 3,1 & 5,6 & $4,3 \mathrm{C}$ \\
$4 \%$ ureia & 2,8 & 5,6 & $4,2 \mathrm{C}$ \\
$4 \% \mathrm{NaOH}$ & 6,1 & 9,3 & $7,7 \mathrm{~A}$ \\
$2 \%$ ureia $+2 \% \mathrm{NaOH}$ & 4,4 & 7,1 & $5,7 \mathrm{~B}$ \\
Média & $4,1 \mathrm{a}$ & $6,9 \mathrm{a}$ & \\
CV $(\%)=8,8$ & & & \\
\hline
\end{tabular}

Médias seguidas de mesma letra minúscula/maiúscula na mesma linha/coluna não diferem pelo teste Tukey a 5\% de probabilidade.
1,0;2,0; 3,0\% - solução comercial a 50\%, Propionato de cálcio, Benzoato de sódio e Sorbato de potássio) e inoculantes bacterianos (Lactobacillus bucheneri e Lactobacillus plantarum) na qualidade de silagens de cana-de-açúcar, e observaram acréscimos de 57,8 e 60,7\% nos teores de cinza da silagem, respectivamente, com $2 \%$ de $\mathrm{NaOH}$ e $3 \%$ de $\mathrm{NaOH}$ em relação à silagem controle.

\section{Conclusões}

Os aditivos químicos ureia e hidróxido de sódio no momento da ensilagem da cana-de-açúcar diminuem as perdas e reduzem os constituintes da parede celular das silagens. O hidróxido de sódio é mais eficiente que a ureia em promover esses benefícios.

\section{Referências}

BALIEIRO NETO, G.; SIQUEIRA, G.R.; REIS, R.A. et al. Óxido de cálcio como aditivo na ensilagem de cana-de-açúcar. Revista Brasileira de Zootecnia, v.36, n.5, p.1231-1239, 2007.

CASTRO NETO, A.; FERREIRA, D.A.; MOLinA, L.R. et al. Avaliação de silagens de cana-de-açúcar submetidas a diferentes tratamentos: II. Proteína bruta, frações fibrosas e digestibilidade "in vitro" da matéria seca. In: REUNIÃO ANUAL DA SOCIEDADE BRASILEIRA DE ZOOTECNIA, 40., 2003, Santa Maria. Anais... Santa Maria: Sociedade Brasileira de Zootecnia, 2003. (CD-ROM).

EVANGELISTA, A.R.; LIMA, J.A.; SIQUEIRA, G.R. et al. Perfil de fermentação da silagem de cana-de-açúcar (Saccharum spp L.). In: REUNIÃO ANUAL DA SOCIEDADE BRASILEIRA DE ZOOTECNIA, 40., 2003, Fortaleza. Anais... Fortaleza: Sociedade Brasileira de Zootecnia, 2003. (CD-ROM).

FREITAS, A.W.P.; PEREIRA, J.C.; ROCHA, F.C. et al. Avaliação da qualidade nutricional da silagem de cana-de-açúcar com aditivos microbianos e enriquecida com resíduo da colheita de soja. Revista Brasileira de Zootecnia, v.35, n.1, p.38-47, 2006a.

FREITAS, A.W.P.; PEREIRA, J.C.; ROCHA, F.C. et al. Características da silagem de cana-de-açúcar tratada com inoculante bacteriano e hidróxido de sódio e acrescida de resíduo da colheita de soja. Revista Brasileira de Zootecnia, v.35, n.1, p.48-59, 2006b.

KUNG JR., L.; STOKES, M.R.; LIN, C.J. Silage additives. In: BUXTON, D.R.; MUCK, R.E.; HARRISON, J.H. (Eds.) Silage science and technology. Madison: American Society of Agronomy, Crop Science Society of America, Soil Science Society of America, 2003. p.251-304.

McDONALD, P.; HENDERSON, A.R.; HERON, S.J.E. The biochemistry of silage. 2.ed. Marlow: Chalcombe Publications, 1991. 340p.

PEDROSO, A.F.; NUSSIO, L.G.; LOURES, D.R.S. et al. Efeito do tratamento com aditivos químicos e inoculantes bacterianos nas perdas e na qualidade de silagens de cana-de-açúcar. Revista Brasileira de Zootecnia, v.36, n.3, p.558-564, 2007.

PEDROSO, A.F.; NUSSIO, L.G.; PAZIANI, S.F. et al. Fermentation and epiphytic microflora dynamics in sugar cane silage. Scientia Agricola, v.62, p.427-432, 2005. 
PEIXOTO, A.M. A cana-de-açúcar como recurso forrageiro. In: PEIXOTO, A.M.; MOURA, J.C.; FARIA, V.P. (Eds.) Pastagens - Fundamentos da exploração racional. 2.ed. Piracicaba: FEALQ, 1994. p.597-633.

PIRES, A.J.V.; REIS, R.A.; CARVALHO, G.G.P. et al. Bagaço de cana tratado com hidróxido de sódio. Revista Brasileira de Zootecnia, v.35, n.3, p.953-957, 2006 (supl. 3).

QUEIROZ, O.C.M.; NUSSIO, L.G.; SCHMIDT, P. et al. Silagem de cana-de-açúcar comparada a fontes tradicionais de volumosos suplementares no desempenho de vacas de alta produção. Revista Brasileira de Zootecnia, v.37, n.2, p.358-365, 2008.

REIS, R.A.; GARCIA, R.; QUEIROZ, A.C. et al. Efeitos da monização sobre a qualidade dos fenos de gramíneas tropicais.Pesquisa Agropecuária Brasileira, v.26, n.8, p.1183-1191, 1991.

RIBEIRO JR., J.I. Análises estatísticas no SAEG (Sistema de análises estatísticas e genéticas). Viçosa, MG: UFV, 2001. $301 \mathrm{p}$.

SCHMIDT, P.; MARI, L.J.; NUSSIO, L.G. et al. Aditivos químicos e biológicos na ensilagem de cana-de-açúcar. 1. Composição química das silagens, ingestão, digestibilidade e comportamento ingestivo. Revista Brasileira de Zootecnia, v.36, n.5, p.1666-1684, 2007 (supl. 2).

SILVA, D.J.; QUEIROZ, A.C Análise de alimentos: métodos químicos e biológicos. Viçosa, MG: UFV, Imprensa Universitária, 2005. 235p.

SIQUEIRA, G.R.; REIS, R.A.; SCHOCKEN-ITURRINO, R.P. et al. Associação entre aditivos químicos e bacterianos na ensilagem de cana-de-açúcar. Revista Brasileira de Zootecnia, v.36, n.4, p.789-798, 2007a.

SIQUEIRA, G.R.; REIS, R.A.; SCHOCKEN-ITURRINO, R.P. et al. Perdas de silagens de cana-de-açúcar tratadas com aditivos químicos e bacterianos. Revista Brasileira de Zootecnia, v.36, n.6, p.2000-2009, 2007b.

VALVASORI, E.; LUCCI, C.S.; ARCARO, J.R.P. Avaliação da cana-de-açúcar em substituição a silagem de milho para vacas leiteiras. Brazilian Journal of Veterinary Research and Animal Science, v.32, n.4, p.224-228, 1995.

Van SOEST, P.J. Nutritional ecology of the ruminant. 2.ed. Corvallis: O \& B Books, 1987. 373p. 